Reflux redux:

Drugs used to treat acid reflux are

scrutinized

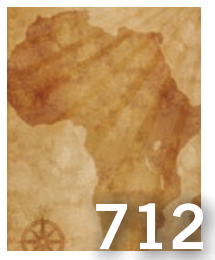

African initiative:

A program announced

by the Wellcome Trust

creates opportunity

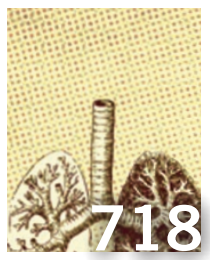

One step ahead:

Researchers try to outwit drug-resistant cancers

\title{
Conflict of interest rules seen by some as too stringent
}

Increasing public and congressional scrutiny has in recent months led many major medical institutions to adopt stricter conflict of interest regulations such as gift bans and consulting restrictions. The new rules are intended to curtail industry influence in medicine. Some physicians, however, argue that they do more harm than good, stifling innovation and hurting patient care.

"I personally think the pendulum has swung past where it had to go," says James Thrall, radiologist-in-chief at Massachusetts General Hospital. "Without robust interaction between practicing physicians and industry, no new technology will become available.”

In April, Johns Hopkins University and Partners HealthCare-which includes Brigham and Women's Hospital, Massachusetts General Hospital and the Harvard Clinical Research Institute-adopted new rules that prohibit employees from accepting meals and gifts from industry and also control how physicians and researchers interact with drug and device manufacturers. Partners' doctors, for example, will no longer be able to earn money by participating in speakers' bureaus. And the new rules at Hopkins prohibit doctors from accepting free drug samples.

Institutions aren't the only ones cracking down. Both Massachusetts and Vermont have adopted state laws that ban industry gifts and require drug companies to report any payments made to health care providers, and Connecticut is considering passing similar legislation.

Even the US National Institutes of Health (NIH) may adopt stricter rules. In May, the agency announced that it is considering expanding its disclosure policy and changing how NIH-funded institutions identify and manage conflicts of interest, among other revisions. New rules would affect many of the researchers and institutions that receive $\mathrm{NIH}$ funding.

The call for conflict of interest reform has been spearheaded, in large part, by Senator Charles Grassley, the ranking Republican on the Senate Finance Committee and cosponsor of a bill that would require drug and device makers to report any money paid to doctors that exceeds $\$ 100$ a year. "The issue for me

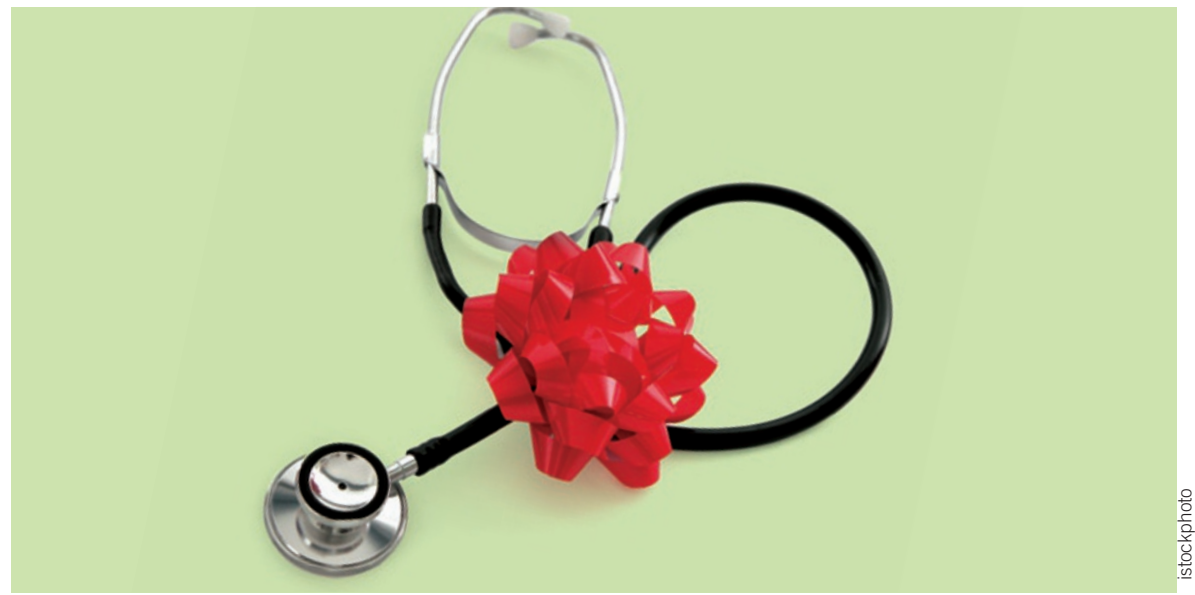

Gifts reconsidered: Some doctors are now speaking out against the new rules

is transparency and the accountability that comes with transparency," he said in an email to Nature Medicine. "The more support there is for timely and accurate disclosure of financial relationships, the better. It tells people there's nothing to hide."

Harvard University has been hit especially hard by Grassley's investigations. Last summer, Grassley accused three Harvard psychiatrists of allegedly receiving underreported earnings from drug makers. In March, he expanded his investigation, asking Pfizer to provide details about whether they made payments over the past couple of years to 149 Harvard faculty members.

Harvard is also home to the reform movement's most outspoken critic: Thomas Stossel, a hematologist and director of translational medicine at Brigham and Women's Hospital in Boston. For the past several years, Stossel has been speaking out against those who seek to curb ties between industry and the medical profession, people he calls 'pharma-scolds'. Now he is working to instigate a counteroffensive. In July, he and his colleagues will launch a new organization aimed at emphasizing the value of physicianindustry interactions. The Association of Clinical Researchers and Educators is scheduled to hold its kickoff meeting 23 July at Brigham and Women's Hospital.

Avi Markowitz, chief of oncology and hematology at the University of Texas Medical Branch (UTMB) in Galveston, will join Stossel as one of the speakers. He says many of the rules serve to harm patients rather than protecting them. For example, Markowitz has several cancer patients who are taking Sanofi Aventis's chemotherapy drug Eloxatin (oxaliplatin). A common side effect is peripheral neuropathy, a condition that causes tingling in a person's fingers and toes when they are exposed to cold. Sanofi Aventis had been providing Markowitz and his UTMB colleagues with free blankets and gloves for those patients. Last fall, however, the university adopted stricter rules banning industry freebies. Now Markowitz can't even accept the unbranded blankets and gloves that Sanofi Aventis has offered to provide.

No one denies that some people have abused the system. But Markowitz says that the entire field is being punished for the actions of "a couple of Bernie Madoffs." There is nothing inherently evil about interacting with industry, yet doctors are being treated like "villains," he says. "If you're in the medical care field, you are guilty until proven innocent."

Stossel would like to see abuses involving financial conflicts of interest treated more like cases of scientific misconduct. Rather than forcing everyone to abide by prohibitive rules, he says administrators should focus on weeding out those who misbehave.

Cassandra Willyard, New York 